\title{
Workshop on High Order Thinking Skills Mathematical Problems to Increase Teachers Teaching Abilities
}

\author{
Defri Ahmad ${ }^{\# 1}$, Syafriandi ${ }^{\# 2}$, Media Rosha ${ }^{\# 3}$ \\ 1,2,3 Mathematics Department, Universitas Negeri Padang \\ Jl. Prof. Dr. Hamka, Air Twar Barat, Padang, Postal Code : 25131, Indonesia \\ * defri_math@fmipa.unp.ac.id; Tel.: +6281374333545
}

Diterima 7 Desember 2019, Disetujui 21 Maret 2020, Dipublikasikan 31 Maret 2020

\begin{abstract}
To accomodate High Order Thinking Skills (HOTS) in classrom, we need to consider curricula, learning process, and assesment. Learning process and assesment have an essential requirement i.e. teacher's ability. Government has done some activity to increase teacher's ability to apply HOTS in classrom, but teachers need more. To keep their motivation and ability, teachers need a continue activity related to HOTS. Lecturer is an academic expert who teach in university level. In Indonesia, service to community is one of obligation for lecturer. Hence increasing teachers understanding about HOTS is one of lecturer's duty. Training and workshops has been designed to rose teachers ability in creating HOTS problems and teaching using those problems. In this activity, teachers are studied about HOTS concept, the government policy about HOTS, solve some HOTS problem in National level test, and how to create HOTS base mathematical problems. For the next activity, teachers are asked to create some HOTS base mathematical problems, and design a learning trajectoty/ design to put their HOTS problem in learning process. Lastly, base on teacher's satisfaction questionnaire, teachers are very happy to get this activity for the activity's programme, mastery of topics, and teacher 's needs.
\end{abstract}

Keywords - HOTS, Mathematics, Training, Workshop, problems unrestricted use, distribution, and reproduction in any medium, provided the original work is properly cited. (C2017 by author and Universitas Negeri Padang.

\section{Pendahuluan}

Istilah HOTS mulai dikenal secara luas semnjak tahun 2013. Pada mulanya dunia Pendidikan mengenal istilah Critical and Creative Thinking Skills (CCTS). Sebagai situasi yang lebih kompleks dari CCTS istilah HOTS mulai muncul. Berbeda dengan CCTS, HOTS juga menuntut kemampuan komunikasi dan bekerja sama serta meminimalkan asesmen yang mengharuskan siswa untuk menghafal suatu fakta.

Istilah HOTS mulai berkembang di Indonesia setelah kesekian kalinya pelajar Indonesia memperoleh skor yang kurang memuaskan pada tes PISA (Program for International Students
Assessment). Tidak jauh berbeda dengan tahuntahun sebelumnya, tahun 2015 Indonesia berada di posisi 65 dari 72 negara [9]. Berdasarkan analisis dari hasil PISA tersebut, kemampuan siswa Indonesia yang masih rendah tersebut meliputi: (1) memahami informasi yang komplek; (2) teori, analisis dan pemecahan masalah; (3) pemakaian alat, prosedur dan pemecahan masalah; dan (4) melakukan Investigasi. Keempat kemampuan ini merupakan kemampuan berfikir tingkat tinggi atau dikenal dengan istilah Higher Order Thinking Skills (HOTS). Kemampuan berfikir tingkat tinggi merupakan salah satu kompetensi penting dalam dunia modern, sehingga wajib dimiliki oleh setiap peserta didik $[10,11,12]$. 
Kemampuan berfikir siswa di Sumatera Barat masih berada di level rendah [7]. Hal ini dipengaruhi oleh berbagai faktor baik yang bersumber dari siswa, guru, dan lingkungan. Sebagai pendidik guru hendaknya memahami karateristik dan menerapkan prinsip-prinsip HOTS di sekolah. Faktanya, pengetahuan guru tentang persoalan yang dapat mengases kemampuan berfikir tingkat tinggi (HOTS) yang masih sangat rendah [8]. Guru masih terbiasa dengan memberikan contoh soal berupa soal dengan level kognisi pengetahuan, pemahaman, dan aplikasi. Contoh-contoh soal yang diterapkan tersebut bahkan belum mampu mengases kemampuan berfikir kritis dan kreatif siswa.

Dalam rangka menyelesaikan permasalahan ini, sebagai salah satu pemerhati sekaligus pelaksana Pendidikan dosen sudah sepatutnya memberikan peran aktif. Peran aktif ini dapat diwujudkan melalui salah satu kewajibannya pada tridharma perguruan tinggi, yaitu pengabdian kepada masyarakat. Universitas Negeri Padang (UNP) merupakan salah satu perguruan tinggi yang aktif dalam menggiatkan dosennya untuk melaksanakan kegiatan pengabdian kepada masyarakat $[2,3,4,6]$. Tahun 2019, UNP menawarkan pelaksanaan kegiatan pengabdian masyarakat dalam beberapa skim, salah satunya yaitu Program Kemitraan Masyarakat (PKM). Program kemitraan masyarakat ini memungkinkan guru untuk melakukan permintaan ke perguruan tinggi untuk peningkatan kualitasnya. Melalui surat permintaan yang dikirimkan MGMP matematika kabupaten lima puluh kota membutuhkan materi terkait pemahaman HOTS serta pelaksanaannya di kelas.

Berdasarkan permintaannya dilakukan analisis situasi melalui wawancara tak terstruktur. Guru mengungkap bahwa mereka belum sepenuhnya memahami istilah HOTS. Guru juga belum begitu memahami soal-soal berbasis HOTS, guru masih terkendala untuk menyelesaikan soal berbasis HOTS apalagi mengajarkannya di kelas. Oleh karena itu, guru di kabupaten lima puluh kota cenderung melaksanakan pembelajaran matematika seperti sebelumnya yaitu memberikan siswa contoh soal dengan level kognisi rendah (Lower Order Thinking Skills).
Jika hal ini terus dibiarkan maka akan sulit sekali bagi siswa - siswa di Indonesia, khususnya kabupaten lima puluh kota untuk memiliki kemampuan berfikir tingkat tinggi. Sehingga kita akan semakin tertinggal dari bangsa-bangsa lain dikarenakan siswa-siswa Indonesia belum memiliki high order thinking skills sebagai akibatnya generasi kedepan akan kesulitan dalam mengaplikasikan pengetahuan yang didapatkan dalam memecahkan permasalahan kehidupan nyata sehingga bangsa Indonesia akan semakin tertinggal dari bangsa lain.

Penyelesaian permasalahan ini tidak hanya menuntut guru untuk memahami HOTS, tetapi juga menuntut guru untuk mampu menciptakan soal-soal berbasis HOTS. Jika guru terus menerapkan pembelajaran matematika dengan memanfaatkan soal HOTS, dan terus mengembangkan diri dengan membuat soal berbasis HOTS. Diharapkan akan tercipta siswasiswa yang mampu beradaptasi dalam menyelesaikan berbagai permasalahan

\section{Solusi}

Solusi yang ditawarkan untuk permasalahan penerapan HOTS secara berkesinambungan yaitu pelatihan dan workshop pemahaman, pembuatan soal, dan perancangan pembelajaran berbasis HOTS kepada guru SMA di MGMP matematika Limapuluh Kota. Adapun materi yang akan disampaikan diantaranya memahami makna istilah HOTS khususnya terkait matematika, menyelesaikan serta memahami kriteria soal matematika berbasis HOTS, merencanakan pembelajaran matematika berbasis HOTS, dan merancang soal matematika berbasis HOTS.

Berdasarkan materi yang disajikan diharapkan dapat/ mampu memberikan solusi kepada guru matematika pada MGMP Matematika Kabupaten Limapuluh Kota. (1) Guru diberikan pemahaman tentang HOTS. (2) Guru dibimbing dalam merencanakan pembelajaran berbasis HOTS. (3) Guru dikenalkan dan diajak untuk membahas soal HOTS yang ada pada soal UN ataupun SBMPTN yang telah ada. (4) Guru diajak untuk merancang soal berbasis HOTS. (5) Guru diajak untuk membahas strategi penerapan/ penggunaan soal yang telah dirancang melalui pendekatan 
saintifik. (6) Guru menerapkan hasil pelatihan ini di kelas.

Dengan soal berbasis HOTS siswa dapat meningkatkan kemampuan berfikirnya dengan baik.

\section{Hasil dan Diskusi}

Kegiatan pengabdian kepada masyarakat ini dilaksanakan dalam dua tahap, yaitu tahap persiapan, dan tahap pelaksanaan. Kedua tahap ini telah dilaksanakan semenjak minggu ketiga Juni 2019, yaitu memulai persiapan hingga minggu kedua desember 2019, yaitu penulisan laporan akhir.

Tahap persiapan dimulai dari perencanaan waktu pelaksanaan workshop, peninjauan lokasi, penyiapan alat dan bahan, dan perizinan guru kepada Stakeholder setempat.

Tahap pelaksanaan pengabdian ini dapat dikelompokan ke dalam enam kategori kegiatan yaitu penyampaian materi atau konsep HOTS, bedah matematika HOTS pada soal Ujian Nasional (UN) dan Seleksi Bersama Masuk Perguruan Tinggi Negeri (SBMPTN), penyampaian materi terkait perancangan pembelajaran berbasis HOTS, workshop penyusunan soal berbasis HOTS, workshop perancangan pembelajaran berbasis HOTS, dan evaluasi.

Materi awal yang diberikan pada tahap awal kegiatan ini, yaitu penyampaian materi umum terkait HOTS. Berdasarkan diskusi yang dilakukan dalam kegiatan pelatihan ternyata konsep HOTS masih samar bagi guru, yaitu sebagian guru masih memaknai soal HOTS adalah soal yang sudah diselesaikan padahal tidak sedangkal itu. Pemateri menjelaskan kepada guru tentang definisi HOTS berdasarkan lampiran edaran pelatihan soal HOTS yang disediakan oleh kemendikbud. Penekanan materi pelatihan awal lebih kepada pengertian HOTS, karakteristik soal HOTS, dan contoh-contohnya.

Materi selanjutnya yaitu mengidentifikasi soal HOTS yang trmuat dalam tes yang akan dihadapi siswa SMA yaitu UN dan SBMPTN. Selain diajak untuk mengidentifikasi soal HOTS tersebut, guru juga dajak untuk menyelesaikan soal tersebut. Berdasarkan diskusi penyelesaian ini ternyata memang soal HOTS terbilang sulit bagi guru.

Kegiatan ketiga dilanjutkan dengan mengubah soal sederhana menjadi soal setipe tetapi sudah menjadi soal HOTS. Guru diarahkan dengan beberapa soal sederhana kemudian guru diminta untuk menjadikannya soal HOTS.

Materi terakhir yaitu guru diajak untuk merancang teknik melaksanakan pembelajaran khususnya materi-materi yang kental dengan soal HOTS. Guru diminta untuk menemukan soal HOTS pada buku ajarnya kemudian guru diajak berdiskusi untuk menyelesaikan soal tersebut serta menyelesaikannya.

Setelah penyampaian materi berakhir kegiatan dilanjutkan dengan workshop. Guru dibagi kedalam kelompok atas kelompok kelasnya yaitu masing-masing dua kelompok guru yang mengajar kelas X, XI, dan XII. Kemudian guru diminta untuk merancang soal HOTS sesuai dengan topik yang akan diajarkannya secara berkelompok. Setelah kegiatan perancangan soal berakhir kegiatan dilanjutkan dengan perancangan pembelajaran dengan memasukan konsep-konsep soal HOTS. Perancangan pembelajaran ini dieratkan dengan pembahasan soal HOTS dan materir yang kental uatan soal HOTSnya.

Pada bagian evaluasi terdapat tiga kegiatan utama yang dievaluasi, yaitu kepuasan peserta terhadap materi yang dipilihkan, kepakaran pelaksana terhadap materi, dan pelaksanaan kegiatan. Ketiga hal ini dievaluasi melalui sebuah lembar evaluasi kegitan, kepuasan peserta terhadap kegiatan pelatihan dan workshop.

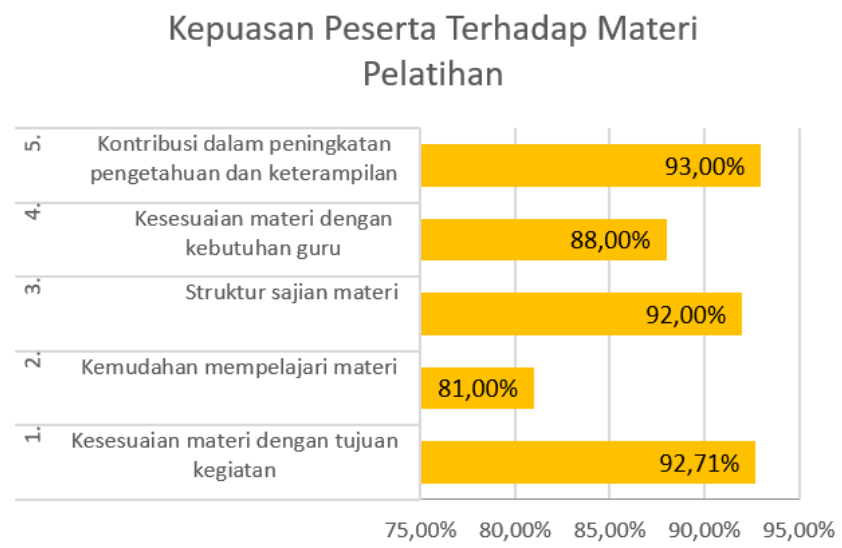

Gambar 1. Kepuasan Peserta Terhadap Materi Pelatihan 
Berdasarkan angket yang disebarkan kepuasan peserta terhadap materi kegiatan secara ringkas disajikan pada Gambar 1. Dari lima item yang ditanyakan peserta sudah sangat puas dengan empat item diantaranya yaitu kontribusi terhadap peningkatan kompetensi guru, kesesuaian materi dengan kebutuhan, struktur sajian, dan kesesuaian materi dengan tujuan kegiatan. Sementara untuk kemudahan materi peserta menyatakan puas. Hal ini sangat sesuai dengan pemilihan topik HOTS yang syarat dengan soal-soal level kognisi C4, C5, dan C6.

Untuk kepakaran pemateri, hasil analisis angket disajikan pada grafik pada Gambar 2 . Berdasarkan pertanyaan yang disajikan dalam enam item, hanya pada satu item peserta yang menyatakan tidak sangat puas, yaitu pada kecepatan penyajian. Kecepatan penyajian materi memang dirasa terlalu cepat. Hal ini disebabkan oleh keterbatasan waktu dan biaya pelaksanaan kegiatan sehingga materi harus kami sampaikan dua kali lebih cepat. Bagian yang paling disukai peserta dari pemateri adalah keteoatan dalam menanggapi permasalahan.

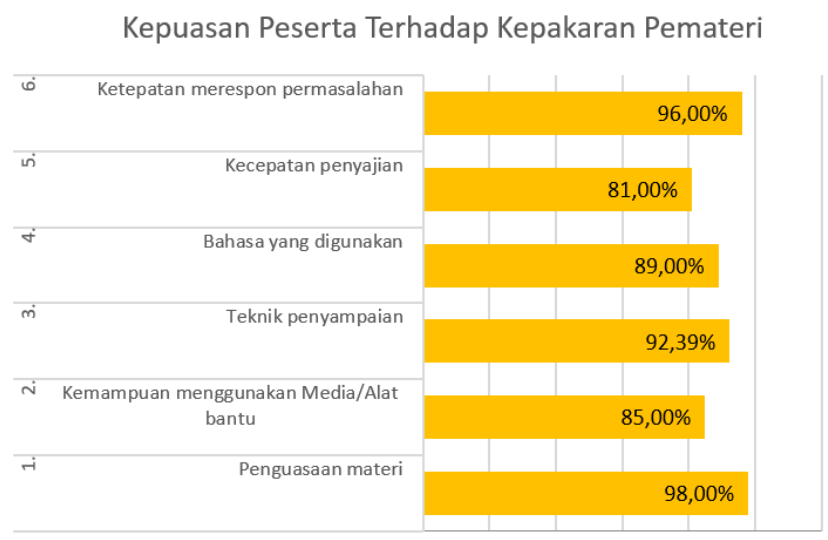

Gambar 2. Kepuasan Peserta Terhadap Kepakaran Pemateri

Terakhir yaitu penilaian peserta terhadap pelaksanaan kegiatan yang meliputi kesigapan panitia, sarana dan prasarana, konsumsi, kesesuaian jadwal, dan kelengkapan KIT. Peserta masih cukup puas dengan ketepatan waktu hal ini dikarenakan lokasi kegiatan yang jauh serta keterbatasan biaya untuk menginap. Selain itu peserta juga hanya menyatakan puas dengan kelengkapan KIT, hal ini dikarenakan peserta tidak disediakan KIT, kami hanya memfasilitas peralatan untuk materi dan bahan workshop.

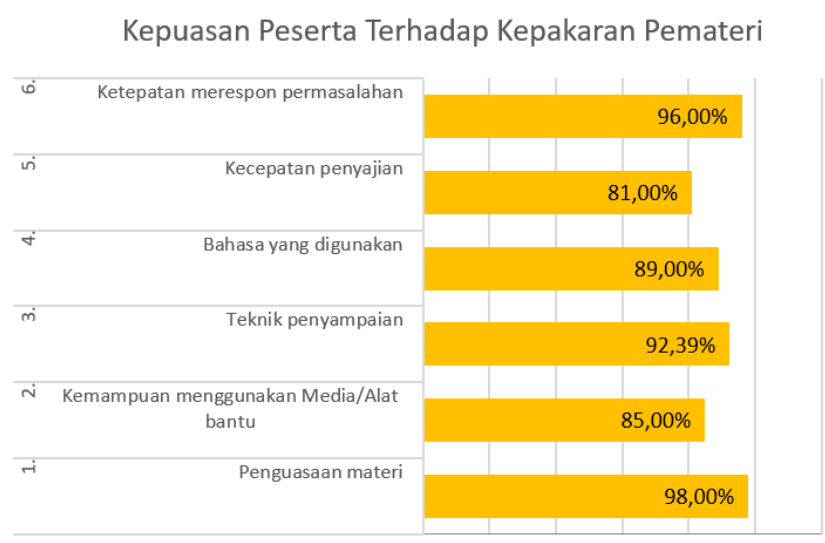

Gambar 3. Kepuasan Peserta Terhadap Pelaksanaan Kegiatan

Dengan demikian terlihat bahwa peserta telah puas dengan pelaksanaan kegiatan.

Pelaksanaan workshop menghasilkan soal dan bahan ajar berupa teknik mengajarkan soal HOTS. Dari kegiatan telah terkumpul kurang lebih empat belas soal HOTS, mulai dari level C2 hingga C6 pada taksonomi Bloom.

Dengan demikian kegiatan ini dilaksanakan dengan cukup sukses dan mampu meningkatan kemampuan pelayanan guru terhadap siswa.

\section{Kesimpulan}

High Order Thinking Skill (HOTS) dipercaya sebagai salah satu hal yang harus dimasukan kedalam proses pembelajaran untuk mempersiapkan siswa untuk menghadapi era perkembangan yang penuh perubahan dan membutuhkan kemampuan problem solving yang tinggi. Namun, guru tidak sepenuhnya siap untuk menerapkan HOTS dalam pembelajaran terutama untuk bidang matematika. Untuk itu perlu dilakukan pelatihan dan workshop yang berkesinambungan kepada guru untuk membuat soal HOTS serta mendiskusikan teknik mengajarkannya. Dengan demikian, Pemahaman guru tentang HOTS, perbendaharaan soal guru, kumpulan strategi pemecahan masalah oleh guru selalu upgrade dan fresh. 


\section{Ucapan Terima Kasih}

Kami mengucapkan terima kasih kepada LP2M UNP (Lembaga Penelitian dan Pengabdian Masyarakat) yang telah mendanai kegiatan ini melalui dana PNBP UNP 2019. Ucapan terima kasih juga kami sampaikan kepada Kepala Dinas Pendidikan Kabupaten Limapuluh Kota serta kepala cabang dinas pendidikan Sumatera Barat Kabupaten Limapuluh Kota yang telah memfasilitasi melalui pemberian rekomendasi dan izin kepada guru pada MGMP Matematika untuk mengikuti kegiatan ini. Seterusnya kepada Kepala SMAN 1 Harau yang telah memfasiltasi tempat serta memberikan pelayanan prima kepada Tim pengabdian Kami.

\section{Pustaka}

[1] Abdullah, Abdul Halim. (2017). Mathematics Teachers' Level of Knowledge and Practice on the Implementation of Higher-Order Thinking Skills (HOTS). EURASIA Journal of Mathematics Science and Technology Education, Vol 13, No 1, pg 3-17

[2] Ahmad, D., Suherman, H. Maulana. 2018. Teacher Mathematical Literacy: Case Study of Junior High School Teachers in Pasaman. IOP Conference Series: Material Sciences and Engineering 335(1), 012109.

[3] Ahmad, Defri; Syafriandi, Syafriandi; Jazwinarti, Jazwinarti. Training and Workshop to Apply Mathematical Literacy in Classroom for Mathematics Teachers in Dharmasraya. Pelita Eksakta, [S.1.], v. 2, n. 1, p. 48-53, apr. 2019. ISSN 2615-0719

[4] Arnellis, Arnellis et al. Olympiad Material Development For Improving of Teacher Professionalism MGMP SMP Regency Of Agam West Region. Pelita Eksakta, [S.1.], v. 1, n. 1, p. 43-46, mar. 2018. ISSN 2615-0719

[5] Arrami M, Garner H. A tale of two citations. Nature. 2008; 451(7177): 397-399.

[6] Fitri, Fadhilah et al. Application Of Mathematical Literacy In Mathematics Learning For Elementary School. Pelita Eksakta, [S.1.], v. 2, n. 2, p. 106108, nov. 2019. ISSN 2615-0719.
[7] Fauzan, Ahmad. (2012). Analisis Literasi Matematis Siswa SMP di Sumatera Barat. Penelitian Profesor. FMIPA UNP. LP2M Universitas Negeri Padang.

[8] Fauzan, Ahmad, dkk (2017). Analisis Kemampuan Guru Matematika SMP di kota Padang dalam merancang soal-soal tipe PISA. Prosiding Seminar Nasional Pembelajaran FISIKA IV. 52-57. Program Studi Magister Pendidikan Fisika FMIPA Universitas Negeri Padang.

[9] OECD 2016 PISA 2015 Assessment and Analytical Framework (Paris: OECD Publishing)

[10] Saido, Gulistan A. M. et al. (2017). Teaching Strategies for Promoting Higher Order Thinking Skills: a case of secondary science teachers. MOJEM: Malaysian Online Journal of Educational Management, [S.1.], v. 3, n. 4, p. 1630, sep. 2017. ISSN 2289-4489

[11] Saragih S. at Al. (2017). Developing Learning Model Based on Local Culture and Instrument for Mathematical Higher Order Thinking Ability. International Education Studies ISSN 1913-9020 (Print), ISSN 1913-9039

[12] Tajudin, NM \& Chinnappan, M. (2017). 'Role of higher order thinking skills in enhancing mathematical problem solving', Man in India, vol. 97 , no. 17

[13] Widana, I Wayan, et al. (2018). Higher Order Thinking Skills Assessment towards Critical Thinking on Mathematics Lesson. International Journal of Social Sciences and Humanities, Vol 2, No 1 pg. 24-32 